\title{
Risk factors for the occurrence of multidrug-resistant tuberculosis among patients undergoing multidrug-resistant tuberculosis treatment in East Shoa, Ethiopia
}

Fanta Desissa ${ }^{{ }^{*}}$, Tilaye Workineh ${ }^{2}$ and Takele Beyene ${ }^{3}$

\begin{abstract}
Background: Multidrug-resistant tuberculosis (MDR-TB) is resistant to the two main first-line anti-tuberculosis drugs: rifampicin and isoniazid. It is a major threat to public health worldwide. The objective of this study was to assess the potential risk factors for multidrug-resistant tuberculosis among patients undergoing MDR-TB treatment at two community hospitals in Ethiopia.

Methods: A case-control study design was conducted from February 1, 2016, to April 29, 2016. TB-positive patients with MDR-TB and non-MDR-TB were considered as cases and controls, respectively. A total of 219 study participants were included in the study. An interviewer-administered structured questionnaire was used to collect primary data from the patients, and a checklist was used to collect data from the clinical records. Bivariate and multivariate logistic regression analyses were used to assess the potential risk factors for the occurrence of MDR-TB.

Results: The odds of developing MDR-TB were higher in patients previously treated with anti-TB drugs (odds ratio [OR] $=6$. 1, 95\%Cl: 2.92-12.62, $P<0.001$ ), those with a history of contact with known TB patients ( $\mathrm{OR}=2.1,95 \% \mathrm{Cl}: 1.04-4.43, P<0.001)$, those living in a rural setting ( $\mathrm{OR}=5.6,95 \% \mathrm{Cl}: 2.14-14.46, P=0.001)$, those with a history of alcohol consumption (OR $=4.3$, 95\%Cl: 2.29-10.49, $P<0.001)$ and those without a job (OR=2.4, 95\%Cl: 1.06-5.42, $P=0.001)$.

Conclusions: The study revealed that contact with known TB patients, previous TB treatment, residence area, lack of a job, and alcohol consumption were potential risk factors for the occurrence of MDR-TB. Enhancing public health education, intensifying directly observed therapy programmes for all TB patients and designing control strategies are recommended.
\end{abstract}

Keywords: MDR-TB, TB, Risk factors, Anti-TB drugs

\section{Background}

Tuberculosis (TB) is an infectious disease caused by the bacillus Mycobacterium tuberculosis. Typically, it affects the lungs and other organs [1]. The disease is spread through the air when people who are sick with pulmonary TB expel the bacteria. Only a small proportion of people, approximately $10 \%$, infected with $M$. tuberculosis will

\footnotetext{
* Correspondence: fantadesissa@gmail.com; fanta.desissa@aau.edu.et ${ }^{1}$ Department of Microbiology, Immunology and Veterinary Public Health, College of Veterinary Medicine and Agriculture, Addis Ababa University, P. O. Box 34, Bishoftu, Ethiopia

Full list of author information is available at the end of the article
}

develop clinical TB during their lifetime, but this probability is much higher among immunocompromised individuals, such as those infected with HIV [2].

Tuberculosis is one of the world's deadliest communicable diseases with most cases in Asia and Africa, including Ethiopia [3-5]. The emergence of multidrug-resistant TB (MDR-TB) is a challenge for the global control and prevention of the disease [6]. Multidrug-resistant tuberculosis is a type of TB that is resistant to at least the two main first-line anti-TB drugs, namely, rifampicin and isoniazid. People become infected with MDR-TB either when they are exposed to a resistant strain or when improper 
treatment leads to selection of a resistant strain [7]. Annually, approximately $3.3 \%$ of new TB patients and approximately $20 \%$ of previously treated patients become infected with MDR-TB, leading to the deaths of 190,000 individuals [1].

Ethiopia is one of the countries with the highest MDR-TB burdens, with $2.3 \%$ of newly confirmed TB patients affected and $17.8 \%$ of previously treated TB patients affected $[1,8,9]$. There is no citable information on the regional prevalence of MDR-TB among newly confirmed and previously treated TB patients, particularly in the Oromia region. However, the first population-based attempt to measure the prevalence of primary and secondary MDR-TB showed a prevalence of MDR-TB of $2.4 \%$ and $14.3 \%$ among newly confirmed and previously treated TB patients, respectively [10]. The rate of MDR-TB detection was estimated to be $33 \%$ among patients with presumptive MDR-TB, which is high compared to other parts of the country [11]. In the region, treatment centre-based management of MDR-TB has been implemented at different hospitals, including Adama Hospital and Bishoftu Hospital. Several factors have been connected to the development of MDR-TB $[8,12]$. Addressing the underlying risk factors is one of the five principal pathways for preventing drugresistant TB [3]. However, there is little citable and comprehensive evidence regarding the potential risk factors that are responsible for the development of MDR-TB in patients undergoing anti-TB treatment in the studied areas. Therefore, the objective of this study was to assess the risk factors associated with MDR-TB among MDR-TB patients following anti-TB treatments at Bishoftu Hospital and Adama Hospital.

\section{Methods}

The study was conducted at Bishoftu Hospital and Adama Hospital between February 1, 2016 and April 29, 2016. These towns are located in the East Shoa Zone, Oromia Regional State, Ethiopia, which is southeast of Addis Ababa, the capital city of Ethiopia. The total populations in Bishoftu and Adama are 100,114 and 422,490, respectively [13]. A case-control study design was employed to determine the risk factors for MDRTB. The source population included all confirmed MDR-TB patients (cases) and non-MDR-TB patients (controls) at Adama Hospital and Bishoftu Hospital undergoing anti-TB treatment during the study period. The study population included all the cases and controls accessible for sampling during the study period.

The inclusion criteria were MDR-TB and non-MDRTB patients who were under treatment follow-up during the study period. MDR-TB patients were confirmed by culture and sensitivity testing. Non-MDR TB patients were either newly or previously treated $\mathrm{TB}$ patients who had smear microscopy that was positive for acid fast bacilli (AFB) or had clinical and/or radiological evidence of disease. Drug-sensitive TB was indicated by smear negative microscopy at the end of the intensive phase of treatment and at the 5th or 6th month of the continuation phase of TB treatment. Patients with non-confirmed MDR-TB or extensively drug-resistant tuberculosis (XDR-TB) were excluded.

A formula from Fleiss' statistical methods for rates and proportions [14] was used to calculate the sample size with Open Epi version 7 statistical packages for Windows based on the following parameters: an estimated exposure of known TB contact for controls (11.3\%) [15], a marginal error of $5 \%$, an estimated odds ratio of 2.8 , $80 \%$ power, a $95 \%$ confidence limit and a 1:2 ratio of cases to controls. Accordingly, the minimum required sample size was 215 . All the MDR-TB patients who were registered and undergoing treatment at both hospitals (13 at Bishoftu Hospital and 102 at Adama Hospital) were targeted for selection due to the small number of cases. The controls were selected from the TB clinic patient registration book. Twenty-four TB patients were selected using a systematic random sampling method from $80 \mathrm{~TB}$ patients who were undergoing anti-TB treatment at Bishoftu Hospital, and 122 TB patients were sampled from 135 TB patients at Adama Hospital. Accordingly, a total of 219 participants including 73 cases (12 from Bishoftu Hospital and 61 from Adama Hospital) and 146 controls (24 from Bishoftu Hospital and 122 from Adama Hospital) were included in the study.

A pre-tested structured questionnaire was used to collect information from the study participants through a direct interview by researchers. A checklist was used to collect data from the clinical records. Training was provided to the individuals who were involved in the data collection process before the beginning of data collection. At the end of each interview, the principal investigator crosschecked the responses to the questionnaire by assessing the uniformity of the responses to multiple questions on the same topic to ensure completeness and data accuracy. Ethical clearance was obtained from the Oromia Health Bureau (Ref no. BEEFO/1-8/1239). A statement about the purpose of the study was read and explained to each study participant. Only those who gave verbal consent to participate in the study were included in the study.

The data were entered into an Excel spreadsheet and exported into SPSS statistical software for analysis. The data were assessed for completeness and consistency by calculating the frequencies of each variable. Bivariate and multivariate logistic regression analyses were carried out to test for the presence of an association between the dependent variable (MDR-TB) and each independent 
variable. Variables with a $P$-value less of than 0.1 in the bivariate analysis were included in the multivariate logistic regression model. For logistic regression, a step-wise forward entry method was used to determine the final model. A $P$-value $<0.05$ in the multivariate logistic regression model was the cut-off point for statistical significance.

\section{Results}

A total of 219 study participants including 73 cases and 146 controls were included in this study. Among the participants, there were relatively more females than males in both the case (54.8\%) and control (58.2\%) groups. The mean age of the study participants in the case and control groups was $32.69(\mathrm{SD}=14.89)$ and 29. $91(\mathrm{SD}=12.57)$ years, respectively.

The univariate analysis showed that the lack of a job, living in a rural setting, a history of imprisonment, marital status, a history of alcohol consumption and cigarette smoking, the site or type of TB, previous TB treatment, a positive smear and a history of contact with a known TB patient were statistically associated with the development of MDR-TB $(P<0.05)$ (Table 1). However, upon conducting the multivariate logistic regression analysis, only a history of contact with a known $\mathrm{TB}$ patient $(\mathrm{OR}=2.1,95 \% \mathrm{CI}$ : 1.04-4.43, $P<0.001)$, previous anti-TB treatment $(\mathrm{OR}=6.1$, 95\%CI: $2.92-12.62, P<0.001)$, living in a rural setting, the lack of a job $(\mathrm{OR}=2.4,95 \% \mathrm{CI}: 1.06-5.42, P=0$. $001)$ and a history of alcohol consumption $(\mathrm{OR}=4.3$, 95\% CI: $2.29-10.49, P<0.001)$ were statistically associated with the occurrence of MDR-TB in the study areas (Table 2).

\section{Discussion}

A case-control study was conducted by recruiting 219 (73 cases and 146 controls) study participants to assess factors associated with developing MDR-TB. Factors such as contact with a known TB patient, previous antiTB treatment, living in a rural setting, the lack of a job and a history of alcohol consumption were found to be statistically associated with the occurrence of MDR-TB. However, many factors related to socio-economic characteristics, personal behaviours and previous $\mathrm{TB}$ treatment-related factors were not statistically associated with MDR-TB in this study. The absence of a statistical association between these factors and MDR-TB in this study does not mean that they are not important factors affecting the occurrence of MDR-TB. These findings may be due to possible variations in the epidemiology of the disease and the socio-economic and health status of the community. Therefore, it is important to mention that the present findings do not mean that these factors are not related to MDR-TB. However, the authors opt to focus the following discussion on those variables that were found to be associated with the occurrence of MDR-TB in the studied areas.

MDR-TB was strongly associated with residence area; living in a rural area increased the occurrence of MDRTB six times compared with living in an urban area. This was similar to a study conducted at the state level in Oromia and in the western part of Ethiopia, which found that rural residents were at higher risk of developing MDR-TB than urban dwellers $[11,16]$. In contrast, residence area was not found to be associated with MDRTB in a study conducted in Addis Ababa and China [17]. This difference may be due to differences in access to TB services, socio-economy and the level of awareness about adherence to first-line TB treatment, as rural communities have poor adherence to treatment that likely leads to MDR-TB. In the current study, marital status was not associated with the occurrence of MDRTB. This is inconsistent with findings that have been reported elsewhere [11]. In contrast, in a study conducted in the Amhara region of the country, it was reported that being widowed was negatively associated with MDR-TB [18].

In this study, the lack of a job was associated with the occurrence of MDR-TB. This was in contrast with another study conducted in the USA, in which no significant difference was found in the occurrence of MDR-TB between the case and control groups [19]. The lack of job is connected with income and is an indicator of low socio-economic status. Several research reports indicated a high burden of MDR-TB among individuals of low socio-economic status $[1,8,20]$. The observed difference might be attributed to differences in income status.

The current study showed that alcohol consumption was associated with the occurrence of MDR-TB. Several reports, including one from the $\mathrm{WHO}$, indicated that the use of alcohol increases the risk of developing MDR-TB due to poor adherence to treatment, impaired immune responses and an increased risk of adverse drug effects. As a result of these conditions, alcohol consumption was identified as an important population-level risk factor for MDR-TB [10, 16, 21]. The occurrence of MDR-TB was strongly associated with previous treatment with anti-TB drugs. This finding was consistent with several previous studies conducted elsewhere that indicated that previous exposure to TB treatment might be the most significant risk for MDR-TB [11, 16-18, 22-29]. The acquired drug resistance of $M$. tuberculosis to anti-TB drugs can occur when there is a history of incomplete or inappropriate TB treatment regimens lasting at least 1 month [30]. This may be because prior inadequate anti-TB treatment only suppresses the growth of susceptible bacilli and does not affect other resistant strains, leading to suitable conditions for the dominant multiplication of pre-existing drug- 
Table 1 Univariate analysis showing the socio-demographic, behavioural and clinical factors associated with multidrug-resistant TB in patients undergoing anti-TB treatment at Adama Hospital and Bishoftu Hospital in the East Shoa Zone, Oromia

\begin{tabular}{llll}
\hline Variables & $\begin{array}{l}\text { Case N } \\
(\%)\end{array}$ & $\begin{array}{l}\text { Control N } \\
(\%)\end{array}$ & $\begin{array}{l}\text { Crude OR } \\
(95 \% \mathrm{Cl})\end{array}$
\end{tabular}

Age (completed years)

$\begin{array}{lllll}<25 & 23(31.5) & 65(44.5) & 1 & \\ 26-45 & 39(53.4) & 62(42.5) & 1.8(0.96-3.31) & 0.700 \\ 46-87 & 11(15.1) & 19(13) & 1.6(0.68-3.95) & 0.274\end{array}$

Sex

Female

$40(54.8) \quad 85(58.2) \quad 0.9(0.49-1.53) \quad 0.629$

Male

$33(45.2) \quad 61(41.8) \quad 1$

Ethnicity

Amhara

19(26) $37(25.3) \quad 1$

Oromo

48(65.8) 95(65.1)

Others

$6(8.2)$

14(9.6)

$0.9(0.51-1.89)$

0.961

Education

Illiterate

Primary

18(24.6)

6) $35(2$

$>$ Secondary

20(27.4)

$35(24)$

0.748

Religion

Muslim

Orthodox

$35(47.9)$

$37(25.3)$

1.1(0.54-2.18)

0.814

$1.1(0.58-2.25)$

0.699

Protestant

$16(21.9)$

$74(50.7)$

1

Others

Residence

$\begin{array}{lllll}\text { Rural } & 23(31.5) & 11(7.5) & 5.6(2.56-12.42) & 0.000 \\ \text { Urban } & 50(68.5) & 135(92.5) & 1 & \end{array}$

Marital status

$\begin{array}{lllll}\text { Single } & 39(39.7) & 82(56.2) & 1 & \\ \text { Married } & 32(43.8) & 58(39.7) & 1.6(0.86-2.86) & 0.149 \\ \text { Divorced } & 12(16.4) & 6(4.1) & 5.7(1.95-16.45) & 0.010\end{array}$

Job status

$\begin{array}{lllll}\text { No } & 27(35.1) & 25(16.9) & 2.8(1.49-5.39) & 0.001 \\ \text { Yes } & 46(64.9) & 121(83.1) & 1 & \end{array}$

History of imprisonment

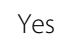

$12(16.4) \quad 12(8.2) \quad 2.2(0.93-5.17) \quad 0.071$

No

$61(83.6) \quad 134(91.8) \quad 1$

Alcohol consumption

$\begin{array}{lllll}\text { Yes } & 40(54.8) & 25(17.1) & 5.9(3.12-11.02) & 0.000 \\ \text { No } & 33(45.2) & 121(82.9) & 1 & \\ \text { History of smoking } & & & & \\ \text { Yes } & 11(15.1) & 10(6.8) & 2.4(0.97-5.98) & 0.057 \\ \text { No } & 62(84.9) & 136(93.2) & 1 & \end{array}$

History of Chewing chat
Table 1 Univariate analysis showing the socio-demographic, behavioural and clinical factors associated with multidrug-resistant TB in patients undergoing anti-TB treatment at Adama Hospital and Bishoftu Hospital in the East Shoa Zone, Oromia (Continued)

\begin{tabular}{lllll}
\hline Variables & $\begin{array}{l}\text { Case N } \\
(\%)\end{array}$ & $\begin{array}{l}\text { Control N } \\
(\%)\end{array}$ & $\begin{array}{l}\text { Crude OR } \\
(95 \% \mathrm{Cl})\end{array}$ & P-value \\
\hline Yes & $21(28.8)$ & $29(19.9)$ & $1.63(0.85-3.12)$ & 0.141 \\
No & $52(71.2)$ & $117(80.1)$ & 1 & \\
Site of TB & & & & \\
$\quad$ Pulmonary TB & $54(74)$ & $83(56.8)$ & $2.2(1.16-3.99)$ & 0.015 \\
Extra Pulmonary TB & $19(26)$ & $63(43.2)$ & 1 & \\
Positive Smear & & & & \\
No & $18(24.7)$ & $19(13)$ & 1 & \\
Yes & $55(75.3)$ & $127(87)$ & $0.5(0.22-0.94)$ & 0.033 \\
Previous TB treatment & & & & \\
No & $25(34.2)$ & $116(79.5)$ & 1 & \\
Yes & $48(65.8)$ & $30(20.5)$ & $7.4(3.66-13.92)$ & 0.000 \\
Contact with a known TB Patient & & & \\
No & $28(38.4)$ & $88(60.3)$ & 1 & \\
Yes & $45(61.6)$ & $58(39.7)$ & $10.1(5.19-19.73)$ & 0.000 \\
HIV status & & & & 0.917 \\
Reactive & $22(30.1)$ & $45(30.8)$ & $0.97(0.53-1.78)$ & \\
Non-reactive & $51(69.9)$ & $101(69.2)$ & 1 & \\
\hline
\end{tabular}

resistant mutants, which is a rise and fall phenomenon $[15,16,31]$. In a similar manner, MDR-TB patients in this study may have experienced similar conditions of previous inadequate treatment that led to the occurrence of MDR-TB.

In this study, cases were more likely to have had contact with $\mathrm{TB}$ patients than controls. The association between contact with known TB patient and MDR-TB was similarly observed in another very recent study conducted in the Oromia region [11]. Several other studies have also supported the hypothesis that contact with a known TB patient is linked with MDR-TB due to exposure to resistant TB resistant [24, 32, 33]. Either the transmission of MDR strains or the selection of singledrug-resistant strains may have contributed to the occurrence of MDR-TB among the cases [24].

The present study is not without limitations. First, the study participants were identified as MDR-TB and non MDR-TB patients only based on their clinical records from the respective TB and MDR-TB treatment centres. Second, due to the small number of MDR-TB patients undergoing anti-TB treatment at both hospitals, several factors, such as HIV status, which are known to be associated with the occurrence of MDR-TB, were not identified. Finally, as a case-control study, there might have been recall bias because some of the information collected was dependent on the recall capacity of the study participants. 
Table 2 Multivariate analysis showing the risk factors for MDR-TB in patients undergoing anti-TB treatment at Adama Hospital and Bishoftu Hospital in the East Shoa Zone, Oromia

\begin{tabular}{|c|c|c|c|c|c|}
\hline Variables & $\begin{array}{l}\text { Case } \\
\mathrm{N}(\%) \\
\end{array}$ & $\begin{array}{l}\text { Control } \\
\mathrm{N}(\%)\end{array}$ & $\begin{array}{l}\text { Crude } \\
\text { OR }(95 \% \mathrm{Cl})\end{array}$ & Adjusted OR(95\%Cl) & $P$-value \\
\hline \multicolumn{6}{|c|}{ Previous treatment } \\
\hline No & $25(34.2)$ & $116(79.5)$ & 1 & 1 & \\
\hline yes & $48(65.8)$ & $30(20.5)$ & $7.4(3.66-13.92)$ & $6.1(2.92-12.62)$ & $<.001$ \\
\hline \multicolumn{6}{|c|}{ Contact with a known TB Patient } \\
\hline No & $28(38.4)$ & $88(60.3)$ & 1 & 1 & \\
\hline Yes & $45(61.6)$ & $58(39.7)$ & $10.1(5.19-19.73)$ & $2.1(1.04-4.43)$ & 0.000 \\
\hline \multicolumn{6}{|l|}{ Residence } \\
\hline Rural & $26(33.8)$ & $6(7.8)$ & $5.6(2.56-12.42)$ & $5.6(2.14-14.46)$ & 0.001 \\
\hline Urban & $51(66.2)$ & $71(92.2)$ & 1 & 1 & \\
\hline \multicolumn{6}{|l|}{ Job status } \\
\hline No & $27(35.1)$ & $25(16.9)$ & $2.8(1.49-5.39)$ & $2.4(1.06-5.42)$ & 0.001 \\
\hline Yes & $46(64.9)$ & $121(83.1)$ & 1 & 1 & \\
\hline \multicolumn{6}{|c|}{ Alcohol consumption } \\
\hline No & $33(45.2)$ & $121(82.9)$ & 1 & 1 & \\
\hline Yes & $40(54.8)$ & $25(17.1)$ & $5.9(3.12-11.02)$ & $4.3(2.29-10.49)$ & 0.000 \\
\hline
\end{tabular}

\section{Conclusions}

The present study revealed that previous exposure to antiTB treatment, contact with known TB patients, living in a rural setting, a lack of a job and alcohol consumption were associated with an increased occurrence of MDR-TB. Enhancing public health education, intensifying the DOT programme for all TB patients, and regular monitoring of the standard treatment programme are recommended. Moreover, further studies should be conducted to clearly establish the epidemiological link and causal relationships between living in a rural setting, the lack of a job and alcohol consumption and the development of MDR-TB. Such findings would contribute to designing tailored control strategies aimed at identifying potential risk factors with particular emphasis on rural communities.

\section{Abbreviations}

DOT: Directly observed therapy; MDR-TB: Multidrug-resistant tuberculosis; OR: Odds ratio; TB: Tuberculosis; XDR-TB: Extensively drug-resistant tuberculosis

\section{Acknowledgements}

The authors acknowledge the Oromia Health Bureau, Adama General Hospital and Medical College, Adama Hospital and Bishoftu Hospital, the data collectors and the TB and MDR-TB patients for their kind cooperation. We also thank Dr. Getahun Agga and American Journal Experts for this edition of the manuscript.

\section{Funding}

No funding was obtained for the research.

\section{Availability of data and materials}

All the data generated during the study are included in the results section. Further information on the data can be obtained upon request from the corresponding author.

\section{Authors' contributions}

FD proposed the research concept and participated in the study design, data collection and analysis, and drafting and revising the manuscript; TW participated in the study design, data analysis, interpretation of the results and revising the manuscript; TB participated in the study design and revising the manuscript. All the authors read and approved the final version of the manuscript.

\section{Ethics approval and consent to participate}

This study was approved by the Oromia Health Bureau (Ref no. BEEFO/1-8/ 1239). A statement about the purpose of the study was read and explained to each study participant. Only those who gave verbal consent to participate in the study were included in the study.

\section{Consent for publication}

Not applicable.

\section{Competing interests}

The authors declare that they have no competing interests.

\section{Publisher's Note}

Springer Nature remains neutral with regard to jurisdictional claims in published maps and institutional affiliations.

\section{Author details}

${ }^{1}$ Department of Microbiology, Immunology and Veterinary Public Health, College of Veterinary Medicine and Agriculture, Addis Ababa University, P. O. Box 34, Bishoftu, Ethiopia. ${ }^{2}$ Adama Hospital Medical College, P. O Box 84, Adama, Ethiopia. ${ }^{3}$ Department of Biomedical Science, College of Veterinary Medicine and Agriculture, Addis Ababa University, P.O. Box 34, Bishoftu, Ethiopia.

Received: 24 November 2016 Accepted: 26 March 2018

Published online: 02 April 2018

\section{References}

1. World health organization. Global Tuberculosis report. Geneva: World health organization; 2015. http://apps.who.int/iris/bitstream/10665/191102/1/ 9789241565059_eng.pdf?u. 
2. European center for disease control. Tuberculosis surveillance and monitoring in Europe. Surveillance report. Stockholm: European center for disease control; 2016. https://ecdc.europa.eu/sites/portal/files/media/en/publications/ Publications/ecdc-tuberculosis-surveillance-monitoring-Europe-2016.pdf.

3. World health organization. Companion handbook to the $\mathrm{WHO}$ guidelines for the programmatic management of drug-resistant tuberculosis. The end TB strategy. 2014. http://apps.who.int/iris/ bitstream/handle/10665/130918/9789241548809_eng.pdf?sequence=1.

4. World health organization. World Health Organization: global tuberculosis control. Geneva: World health organization; 2013. http://www.who.int/iris/handle/10665/91355.

5. Federal Ministry of Health. Guideline for program and clinical management of drug resistant tuberculosis. 2009.

6. World health organization. World Health Organization: WHO report 2011. Geneva: Global Tuberculosis Control; 2011. http://www.who.int/iris/handle/ $10665 / 44728$.

7. World health Organization. Treatment of tuberculosis guidelines. Geneva: World health Organization; 2010. https://www.ncbi.nlm.nih.gov/books/ NBK138748/.

8. Federal minstry of health. Federal Ministry of Health health and health related indicators 2005 E.C (2012/2013). 2014.

9. Ethiopian public health institute. Report on national TB / HIV sentinel surveillance. 2015

10. Hamusse SD, Teshome D, Hussen MS, Demissie M, Lindtjørn B. Primary and secondary anti-tuberculosisdrug resistance in Hitossa District of ArsiZone, Oromia regional state, Central Ethiopia. BMC Public Health. 2016;16:593.

11. Mulisa G, Workneh T, Hordofa N, Suaudi M, Abebe G. Multidrug-resistant Mycobacterium tuberculosis and associated risk factors in Oromia region of Ethiopia. Int J Infect Dis. 2015;39:57-61.

12. Abdel O, Akl M, Ali A, Mahalli E, Abdel O, Akl M, et al. Drug Resistant Tuberculosis: Risk Factors and Resources-Utilization at a Chest Disease Clinic, Alexandria, Egypt. J Am Sci. 2012;8(4):107-12.

13. Central Statistical Authority of Ethiopia. The 2007 population and housing census result of Ethiopia. Addis Ababa: UNFPA; 2007.

14. Kelsey $\mathrm{J}$, Whittmore AS, Evans As, Thompson WD. Methods in Observational Epidemiology. 2nd Edn, Oxford university press, Newwork; 1996

15. Casal M, Vaquero M, Rinder H, Tortoli E, Grosset J, Gutiérrez J, et al. A casecontrol study for multidrug-resistant tuberculosis: risk factors in four European countries. Microb Drug Resist. 2005;11(1):62-7.

16. Mekonnen F, Tessema B, Moges F, Gelaw A, Eshetie S, Kumera G. Multidrug resistant tuberculosis: prevalence and risk factors in districts of metema and west armachiho, Northwest Ethiopia. BMC Infect Dis. 2015;15:461.

17. Tadesse F. Risk factors for multi-drug resistant tuberculosis in Addis Ababa,Ethiopia. J Public Health. 2015;3(2):65-70.

18. Mulu W, Mekonnen D, Yimer M, Admassu A, Abera B. Risk factors for multidrug resistant tuberculosis patients in Amhara National Regional State. Afri Health Sci. 2015;15(2):368-77.

19. Khan $\mathrm{R}$. The social determinants of multidrug resistant tuberculosis in the United States between 2005 and 2009. Georgia: Thesis, gerogia state university; 2013. https://scholarworks.gsu.edu/cgi/viewcontent.cgi?article= $1288 \&$ context $=$ iph theses.

20. Mishra P, Hansen EH, Sabroe S, Kafle KK. Socio-economic status and adherence to tuberculosis treatment : a case-control study in a district of Nepal. Int J Tuberc Lung Dis. 2005;9:1134-9.

21. Liang Y, Harris FL, Brown LAS. Alcohol induced mitochondrial oxidative stress and alveolar macrophage dysfunction. Biomed Res Int. 2014;2014:371593.

22. Biadglegne F, Sack U, Rodloff AC. Multidrug-resistant tuberculosis in Ethiopia : efforts to expand diagnostic services, treatment and care. Antimicrob Resist Infect Control. 2014;3:31.

23. Chen $S$, Huai $P$, Wang $X$, Zhong J, Wang $X$, Wang $K$, et al. Diseases risk factors for multidrug resistance among previously treated patients with tuberculosis in eastern China : a case - control study. Int J Infect Dis. 2013;17:12.

24. Ms F, Mn A, Afroz S, Islam S, Alam A, Hossain M. Risk factors of multi-drugresistant tuberculosis in Bangladeshi population : a case control study. Bangladesh Med Res Counc Bull. 2013;39:34-41.

25. Weyenga $\mathrm{OH}$. Factors associated with multi-drug resistant tuberculosis in Kenya. A Msc thesis, Jomo Kenyatta University of Agriculture and Technology. 2011. http://journals.jkuat.ac.ke/index.php/pgthesis_abs/article/view/659.

26. Tessema B, Beer J, Emmrich F, Sack U, Rodloff AC. First- and second-line anti-tuberculosis drug resistance in Northwest Ethiopia. Int J Tuberc Lung Dis. 2012;16:805-11.
27. Abebe G, Abdissa K, Abdissa A, Apers L, Agonafir M, Bouke C, et al. Relatively low primary drug resistant tuberculosis in southwestern Ethiopia. BMC Res Notes. 2012;5(1):1.

28. Agonafi M, Lemma E, Goshu S, Santhanam A, Girmachew F. Phenotypic and genotypic analysis of multidrug-resistant tuberculosis in Ethiopia. Int J Tuberc Lung Dis. 2010;14:1259-65.

29. Hirpa S, Medhin G, Girma B, Melese M, Mekonen A, Suarez P. Determinants of multidrug-resistant tuberculosis in patients who underwent first-line treatment in Addis Ababa : a case control study. BMC Public Health. 2013; 13(1):1.

30. Rieder HL. Interventions for tuberculosis control and elimination. Paris: IUATLD; 2002

31. Baghaei $P$, Tabarsi $P$, Chitsaz E, Novin A, Alipanah N. Risk factors associated with multidrug-resistant tuberculosis. Tanaffos. 2009;8:17-21.

32. Rahman MA, Hussain MW, Alam F, Jahan MS. Multi-drug Resistant Tuberculosis : Experience in Bogra. J Teachers Association. 2005;18(1):30-6.

33. Ahmad AM, Akhtar S, Hussain SF, Rizvi N. Risk factors for multidrug-resistant tuberculosis in urban Pakistan : a multicenter case - control study. Int J Mycobacteriol. 2012;1(3):137-42.

\section{Submit your next manuscript to BioMed Central and we will help you at every step:}

- We accept pre-submission inquiries

- Our selector tool helps you to find the most relevant journal

- We provide round the clock customer support

- Convenient online submission

- Thorough peer review

- Inclusion in PubMed and all major indexing services

- Maximum visibility for your research

Submit your manuscript at www.biomedcentral.com/submit
C) BioMed Central 